A R RVIEW $\begin{array}{r}\text { FOOD SCIENCE } \\ \text { RESEARCH JOURNAL }\end{array}$

\title{
Food for therapy: Naturopathic dietetics approach !
}

\author{
Prachi Avinash
}

Food plays one of the most important roles in maintaining good health and managing diseases. Plant food constitutes a significant part of our diet providing various important nutrients required by body for adequate growth and development. The philosophy about therapeutic benefits of food, it being health promoting beyond its nutritional value has gained acceptance. It is a common practice to envisage that a person can eat whatever he/she feels like and as long as no direct bad after-effects are felt, the matter deserves no attention. But in reality, this is only a wrong notion and it beckons the beginning of a disease or disorder. Regularity, punctuality, thorough chewing, feeling of hunger and avoiding hurry, worry, tension and emotion while taking meal are very essential to derive maximum benefits and best utilization of nutrients from the food intake.With the many different types of diets and lifestyles based on both ideologies and allergies, a lot of nutritional choices are available to the consumers now-a-days. A naturopathic diet can be beneficial in preventing illness, improving metabolism and overall health. It works on principle of foods intheir natural state, i.e. foods free from artificial ingredients, chemical preservatives and additives. In modern times, because of advancement in technology, familial advices, natural/ synthetic products on sale, media spins, muddled messages, etc. the people are bound to get complicated and confusing cognizance regarding how to maintain health through diet and nutrition. It undeniably becomes perplexing when we have to decide what we should actually consume and what should we avoid. Thus, it was felt necessary to compile the knowledge of naturopathy and dietetics overlap through this paper, so as to provide an insight of naturopathic dietetics.

Key Words : Dietetics, Naturopathy, Diet therapy, Food, Medicine

How to cite this article : Avinash, Prachi (2020). Food for therapy: Naturopathic dietetics approach ! Food Sci. Res. J., 11(2): 213216, DOI : 10.15740/HAS/FSRJ/11.2/213-216.Copyright@ 2020: Hind Agri-Horticultural Society. 